\title{
The positive aspects of attention deficit hyperactivity disorder: a qualitative investigation of successful adults with ADHD
}

\author{
Jane Ann Sedgwick ${ }^{1,2} \oplus \cdot$ Andrew Merwood ${ }^{2} \cdot$ Philip Asherson $^{2}$
}

Received: 25 May 2018 / Accepted: 19 October 2018 / Published online: 29 October 2018

(c) The Author(s) 2018

\begin{abstract}
The behavioural characteristics of ADHD do not exist in binary form (i.e. normal vs. abnormal); instead, they exist on a spectrum or continuum. This implies that some aspects of ADHD can be adaptive rather than impairing, or some adults may possess certain strengths or attributes that mediate and/or compensate for their ADHD-related deficits or impairments. More research is needed to clarify these observations. To explore and describe positive aspects of ADHD from the perspective of successful adults with ADHD. A phenomenological approach with open-ended interviews was used to collect data. The interviews were audio taped, transcribed verbatim and analysed using thematic content analysis. Six core themes (cognitive dynamism, courage, energy, humanity, resilience and transcendence) defined by 19 sub-themes were found. These themes were compared against attributes catalogued in the character strengths and virtues (CSV) handbook and classification for positive psychology. Two core themes (cognitive dynamism and energy) were not listed as virtues in the CSV, and neither were six sub-themes (divergent thinking, hyper-focus, nonconformist, adventurousness, self-acceptance and sublimation) listed as behavioural traits. We propose these constructs as positive aspects specific to ADHD, and the other constructs, as positive aspects relevant to people in general, with or without ADHD. This study offers insights into positive human qualities, attributes or aspects of ADHD that can support and sustain high functioning and flourishing in ADHD life. This study also addresses the question in the disability research about "how we might reconsider the behaviours associated with ADHD so that they are seen as valuable and worthy of conservation?".
\end{abstract}

Keywords Attention deficit hyperactivity disorder $\cdot$ ADHD $\cdot$ Positive aspects $\cdot$ Positive attributes $\cdot$ High-functioning $\cdot$ Flourishing

\section{Introduction}

ADHD is a neurodevelopmental disorder characterised by impairing levels of inattention, hyperactivity and impulsivity that tends to begin in childhood and often persists into adulthood. In adults, ADHD is often associated with poor outcomes in domains related to academic achievement, work performance and social relationships (Able et al. 2007). However, ADHD is highly heterogenous, with its behavioural characteristics that exist on a

Jane Ann Sedgwick

jane.sedgwick@kcl.ac.uk

1 Florence Nightingale Faculty of Nursing, Midwifery and Palliative Care, King's College London, London, UK

2 Social, Genetic and Developmental Psychiatry Centre, Institute of Psychiatry, Psychology and Neuroscience (IoPPN), King's College London, London, UK spectrum (Lubke et al. 2009). There is increasing acceptance that many mental health conditions including ADHD are dimensional disorders and that not all symptoms are associated with deficits or functional impairments (Epstein and Loren 2013). For instance, "high-functioning ADHD", described by Weiss (2016), refers to adults who meet diagnostic criteria for ADHD, but are still able to function relatively well. Lesch (2018) concurred with this definition of "high-functioning (HF)-ADHD" and noted positive attributes like hyper-focus, eidetic learning, putting in twice as much effort, as examples of compensatory strategies that could be used to mitigate ADHD-related deficits or impairments. This definition of HF-ADHD is used within this study. This definition aligns with the notion that mental health is not only about absence of illness or disorder, but also about recovery, coping, well-being and flourishing (Repper and Perkins 2006; Seligman 2012). At the turn of the millennium, Seligman and Csikszentmihalyi (2000) 
introduced positive psychology to move away from a deficit-focused view of mental health, towards approaches that were more enabling, strength-based and emphasised positive aspects of human functioning and flourishing (i.e. positive emotions, engagement, relationships, meaning and accomplishment) (Seligman 2012). In his recent editorial, Lesch (2018) also stated that "the time is ripe to intensify discussion about how research on ADHD can be moved away from the deficit-focused view to a concept that is oriented towards resources a patient might be able to recruit, thus, from a psychopathologic definition to the individual's potential to function at a high level despite impairment's in attention, motor control, cognition and emotional regulation" (p. 191).

A search for the literature about the positive aspects of ADHD mainly yielded results about treatment. We do not doubt that treating ADHD in adults has many benefits (Kooij et al. 2010). But the point is hardly any empirical research was found about the positive aspects of ADHD. One study correlated high creativity with ADHD in adults (e.g. White and Shah 2006, 2011). In another international qualitative study, Mahdi et al. (2017) used focus group discussions and semi-structured interviews with 76 participants from five countries (Brazil, India, Saudi Arabia, South Africa and Sweden). The aim of this study was to explore ability and disability in ADHD from the participants own perspective using the WHO International Classification of Functioning, Disability and Health (ICF) framework. Pertinent findings were that although the participants reported a number disabling impairments in daily life, they also described positive aspects of ADHD (i.e. high levels of energy and drive, creativity, hyper-focus, agreeableness, empathy and a willingness to assist others). Mahdi et al. concluded that there was a need to appraise ADHD more broadly, extending beyond diagnostic criteria and into areas of ability versus disability, environmental facilitators versus barriers. The present study is therefore timely. It is one of the first to offer a meaningful contribution to contemporary research about the positive aspects of ADHD. Our overarching aim was to describe the nature and defining features of these positive aspects from the viewpoint on successful adults with ADHD (i.e. HF-ADHD and flourishing defines successful).

\section{Methods}

Phenomenology was the most suitable theoretical framework for this qualitative investigation, because it is a research design founded in a paradigm of personal knowledge and lived experience (Husserl 1983; Giorgi 2008). To study phenomena, like the positive aspects of ADHD, as they are consciously experienced by successful adults with ADHD, requires not only empathy, but the ability to establish good rapport with participants in a relatively short period of time (Creswell and Poth 2017). We also needed to recruit participants with specific knowledge and lived experience, who were able to articulate their views and perceptions. Therefore, we used purposive sampling to identify and select participants for this study. Patton (1990) explained that "the logic and power of purposeful sampling lies in selecting information-rich cases to study in depth....... Information-rich cases are those from which a researcher can learn a great deal about issues of central importance to the purpose of the study" (p. 169). Since there are different types of purposeful sampling strategies, the strategies we used are listed in Table 1.

We recruited six successful (i.e. HF-ADHD and flourishing) adult males aged between 30 and 65 years from an NHS tertiary service in London. These participants had been recently diagnosed with ADHD and prescribed medication. They were all in gainful and/or professional employment. Four participants were parents and in longterm relationships. We used open-ended interviews to collect data. The second author conducted all the interviews by asking three questions: (1) What do you think are the advantages and disadvantages of having ADHD? (2) Please describe a time when you felt that your ADHD helped to achieve something? (3) What aspects of your ADHD would you miss if it went away? The interviews lasted up to $1 \mathrm{~h}$ and were audio taped. Postgraduate students were paid to transcribe the audio tapes, and the transcriptions were given to the first author for analysis. Thematic content analysis (TCA), a method developed from grounded theory and content analysis (Glaser and Strauss 1967; Babbie 1973), was used to analyse the interview data. TCA is one of the most common

Table 1 Purposeful sampling strategies used in this study (Palinkas et al. 2015)

\begin{tabular}{ll}
\hline Strategy & Objective \\
\hline Homogeneous & To identify and select cases with knowledge and experience of the positive aspects of ADHD \\
Typical case & To describe what is typical, normal or average \\
Stratified purposeful & To capture different (or varying) views rather to identify a common core, although common- \\
alities may emerge in the analysis of data
\end{tabular}


methods used for analysing qualitative research data. It is a method that employs a structured (or systematic) approach to retrieve meaningful data from written texts. The texts are first coded, the coded data are categorised under common themes, which are then formulated into core themes that constitute the main findings of the study. The report of the findings should offer rich descriptions of the participants personal knowledge and lived experience (Burnard et al. 2008). The TCA procedures that we used are listed in Table 2 below. Scrupulous attention to reliability and validity (i.e. rigour) is essential in qualitative research. Therefore, we used Lincoln and Guba's (1985) attributes of "trustworthiness" to appraise the rigour of this study (see Table 3).

\section{Findings and discussion}

The main findings of this study are characterised by six core themes (cognitive dynamism, courage, energy, humanity, resilience and transcendence), further defined by 19 subthemes. These are listed in Table 4, which is headed by the core themes, and the defining sub-themes are listed under each one. These themes were compared with the attributes

Table 2 TCA procedure (Burnard et al. 2008)

\begin{tabular}{l} 
i. \\
$\begin{array}{l}\text { ii. } \\
\text { iii. }\end{array}$ \\
$\begin{array}{ll}\text { iv. } & \text { Collapse the coded data under potential themes. Work through the themes and cross out duplications } \\
\text { v. } & \text { Ensure each theme is clearly named and defined } \\
\text { vi. } & \text { Handover the thematic data, with excerpts from the participants, to the researcher team for review and to finalise the core } \\
\text { vii. } & \text { Find sub-themes }\end{array}$ \\
\hline
\end{tabular}

Table 3 Attributes of trustworthiness (Lincoln and Guba 1985)

\begin{tabular}{|c|c|c|}
\hline Attribute & Description & How was it achieved \\
\hline Truth-value & $\begin{array}{l}\text { The extent to which a study explores what is was supposed to } \\
\text { explore }\end{array}$ & $\begin{array}{l}\text { This study describes positive aspects of ADHD from the per- } \\
\text { spective of the participants }\end{array}$ \\
\hline Applicability & $\begin{array}{l}\text { The extent to which the findings are relevant to other people or } \\
\text { fields of study }\end{array}$ & $\begin{array}{l}\text { The themes found in this study were peer reviewed and then } \\
\text { finalised. The findings are discussed in relation to the existing } \\
\text { literature. Other studies and plethora of anecdotal evidence } \\
\text { confirm similar positive aspects of ADHD as reported in this } \\
\text { study }\end{array}$ \\
\hline Consistency & $\begin{array}{l}\text { The extent to which readers can make sense of the research } \\
\text { design and method }\end{array}$ & $\begin{array}{l}\text { The aims of this study, phenomenological approach, interview } \\
\text { questions, process of TCA are outlined and discussed }\end{array}$ \\
\hline Neutrality & The extent to which the research process is free of bias & $\begin{array}{l}\text { One researcher conducted the interviews, postgraduate students } \\
\text { transcribed the audio taped interviews, another researcher } \\
\text { analysed the data and the themes were peer reviewed. The } \\
\text { findings are discussed in relation to the existing literature; } \\
\text { excerpts from the interviews are cited in text. Truth-value, } \\
\text { applicability and consistency have also been achieved }\end{array}$ \\
\hline
\end{tabular}

Table 4 Core themes and defining sub-themes that represent the positive aspects of ADHD

\begin{tabular}{|l|l|l|l|l|l|}
\hline COGNITIVE DYNAMISM & \multicolumn{1}{|c|}{ COURAGE } & ENERGY & HUMANITY & RESILIENCE & TRANSCENDENCE \\
\hline Divergent thinking & Non-conformist & Spirit & Social intelligence & Self-regulation & $\begin{array}{l}\text { Appreciation of } \\
\text { Beauty } \\
\text { excellence }\end{array}$ \\
\hline Hyper-focus & Adventurousness & Psychological & Humour & Sublimation & \\
\hline Creativity & Bravery & Physical & Self-acceptance & \\
\hline Curiosity & Integrity & & $\begin{array}{l}\text { Recognition of } \\
\text { feelings }\end{array}$ & \\
\hline & Persistence & & & \\
\hline
\end{tabular}


catalogued in the character strengths and virtues (CSV) handbook and classification of the "sanities" in positive psychology (Peterson and Seligman 2004). The CSV identifies six core virtues (wisdom and knowledge, courage, humanity, justice, temperance and transcendence), considered to be good by most cultures throughout history. These core virtues are akin to the cardinal and theological virtues of Aristotle and Aquinas (faith, hope, charity, prudence, courage, justice, fortitude and temperance) (Cooper 1998). The CSV virtues are further defined by 24 character strengths (or behavioural traits) that when practised are said to promote and sustain well-being and flourishing (Peterson and Seligman 2004). In Table 4, the core themes: courage, humanity, resilience, transcendence, and sub-themes: creativity, curiosity, bravery, integrity, persistence, spirit, enthusiasm, vitality, vigour, social intelligence, humour, self-regulation, appreciation of beauty and excellence, are highlighted in a green colour because they were listed in the CSV. This finding suggested that these positive attributes or aspects are relevant to people in general, with or without ADHD. As shown in Table 4, the core themes: cognitive dynamism and energy, and the sub-themes: divergent thinking, hyper-focus, nonconformist, adventurousness, self-acceptance and sublimation, are not highlighted, because they were not listed in the CSV. We propose these attributes as specific positive aspects of ADHD. We report and discuss these findings are discussed in relation to the existing/relevant literature. Excerpts from the interviews are cited in text, to illustrate how the themes emerged and to give examples of the participants reports in their own words (Creswell and Poth 2017).

\section{Cognitive dynamism}

Cognitive dynamism as the first core theme conceptualised the ceaseless mental activity that was reported by all the participants. The participants described spontaneous and non-sequential thought processes, flashes of images, as well as episodes of intense mental focus. Defining sub-themes were divergent thinking, hyper-focus, creativity and curiosity. Divergent thinking (DT) refers to an ability to generate novel, original or ingenuous ideas, as such, it is a measure of creativity (Guilford 1967). The participants described DT as a natural aspect of their ADHD. They reported being swamped by ideas that fleeted from one to the next or being "outside-the-box" thinkers, but then also being able to hyper-focus on tasks or activities that they found interesting. Hyper-focus in ADHD is said to be a deficit in set-shifting and task-switching (Miranda et al. 2012), but for the participants, hyper-focus was associated with productivity. This reflects in the view of one participant who said:

...being a therapist is like giving your ADHD brain caviar.... being able to channel all that random energy that's flying around in my head into one intense hyper- focused sort of beam...that's what I mean by caviar for the brain....it is giving the brain a task that it's almost designed for..... if you thought that an ADHD brain had been designed for something.... because I think the energy that the ADHD brain seems to have....it's unfocused, quite scattered, chaotic and a bit random... but give that brain something that really you can tune into and it's your interest, then all that random stuff just goes boom... I get this incredible intense concentration and that's great for work....

The participants descriptions of hyper-focus were akin to a state of flow. Csikszentmihályi and Csikszentmihályi (1988) defined flow as a state of intense concentration, energised attention, complete absorption in an activity that "produces intense feelings of enjoyment" (p. 15). Fitzgerald (2010) also noted that the "focused work rate that hyperfocus produces enables creative genius to flourish". Creativity is multifaceted, with numerous expressions and psychosocial influences, but for it to be effective in real-time, it requires originality and ingenuity (Piirto 1998). Research has found that adults with ADHD had more real-time creative achievements than adults without ADHD (White and Shah 2006, 2011). Such findings echo in the report of one participant who said:

I'm an artist.... a creative type... a bohemian.... you are most likely to be a creative person if you are a divergent thinker.... and not convergent.....I am very creative and that's through and through....I' $m$ a fine art graduate, a musician, a published poet, an entrepreneur, a performer...

All the participants described naturally being curious as a positive aspect of ADHD. Curiosity refers to inquisitiveness, openness to experience, a desire to learn, and it may also be a mechanism that allows people to pursue their ambitions and discover meaning in life (Zuss 2012).

\section{Courage}

Courage as the second core theme conceptualised the participants reports about living with ADHD, confronting fear and dealing with uncertainly. This construct includes psychological and moral attributes associated with equity, social justice and human rights (Putman 2001). Defining sub-themes are nonconformist, adventurousness, bravery, integrity and persistence. All the participants reported being viewed by others as nonconformist. They spoke about always having felt different, like they were outsiders or people resistant to social or cultural modification (i.e. acculturation). Hegel (1807/1977) was first to coin the phrase a "struggle for recognition", before it was adapted by Honneth (1995), to describe misrecognition as a social process. According 
to Honneth misrecognition occurred when people did not respect each other, and it caused social tension or conflict. The misrecognition of ADHD as a disability accentuates how labelling or stereotyping can be used by society to judge whether people with ADHD can fit into certain social groups or settings or have access to social opportunities. People with ADHD often do not fit in and so they become outsiders (Becker 1963). Being an outsider and having an "outsiders' identity" was described by one participant who said:

..... not fitting into mainstream education system firstly made me feel like an outsider.... But I think also ethnically... the way I grew up had a part of it as well.... because I didn't fit there .....and going to art college.... I didn't fit in there either.... there's a lot of positives with ADHD but there tends to be a lot of people who are outsiders....

From the participants reports, it was apparent that being brave, or bravery, was a positive resource for overcoming the struggle for recognition and individuating. Individuation is about transcending restrictive social norms and beliefs (Jung 1921), by resisting acculturation (Maslow 1951), or through self-determination (Ryan and Deci 2000). The participants seemed to associate bravery with their natural sense of adventurousness, spontaneity and thrill-seeking. One participant said:

...Well, thrill-seeking is an ADHD thing.... I can list in my life having done white water rafting, bungee jumping, hand-glider pilot, riding a rocket ship motorcycle at the age of 60 , which I really ought not to be now.... travelling to far flung places....so just adventure, novelty seeking, thrill-seeking.....I have done a lot in my life and achieved a lot and experienced a lot..... I would see a lot of that as being quite positive and a lot of that is ADHD drive...

Adventurousness tends to be associated with risk-taking in ADHD, or with impulsivity, which is one of the core symptoms in ADHD. But for the participants in this study, being adventurous was described as fun, while impulsivity and spontaneity were described as the same thing. The participants said that an action was judged as either impulsive or spontaneous depending on how other people reacted to it. If the reaction of others was negative, then the action (or behaviour) was viewed as impulsive, but when the reaction was positive, then the action was described as spontaneous (or intuitive). One participant explained:

...it's interesting because being spontaneous that's kind of being impulsive...it's the same thing.... say an action can be described as impulsive if you say something inappropriate... or spontaneous if you say something which might be cute or might be funny...
A willingness to be brave or to take risks and be responsible for one's actions relates to integrity. The participants said that being open about having ADHD made them feel authentic and honest, which are attributes that characterise integrity (Carter 1996). A hallmark of authentic behaviour and autonomy is intrinsic motivation. Ryan and Deci (2000) said "when intrinsically motivated, a person is moved to act for the fun or challenge entailed rather than because of external products, pressures or reward" (p. 56). It seemed like the participants intrinsic motivation allowed them to maintain a positive sense of self despite disclosing (or being open) about their disability. This certainly requires courage given the associations of ADHD with poor educational outcomes, criminality, substance misuse, socio-economic disadvantage and so on (Bernfort et al. 2008). The participants intrinsic motivation could also have been the driver for their impulsive and/or spontaneous adventures, or curiosity or the persistence they said was useful for achieving their goals (Von Culin et al. 2014).

\section{Energy}

Energy as the third core theme conceptualised the participants' reports about their internal experiences and capacity for action. All the participants described an abundance of energy that they positively attributed to their ADHD. Defining sub-themes are spirit, psychological and physical. Spirit often relates to the soul or chi, which is an omnipresent energy that connects man with nature (Puthoff 2002). More broadly, spirit relates to a subjective experience that embraces higher aspects of self, sense of purpose and meaning in life (Walsh and Vaughan 1993). The participants described exuberance as the spirit of ADHD. One participant said:

...I've got all this energy.... a lot of energy.... whatever it's to do with.... nature/nurture/spiritual stuff....

While another said:

...I think there's a sort of spirit... I can only talk about myself...but I mean...there's a spirit of adventure in my ADHD....

All the participants described being distinctly aware of being connected to something much bigger than themselves. These reports seemed to align best with Jung's (1938a, b) view of self (or soul) as a fundamental archetype of spiritual centredness with a role to guide people towards individuation and a relationship with the "luminous" or 'light of nature' (i.e. collective unconscious). Some participants said they wanted to learn how to harness the energy of their ADHD, so that they could direct it at will for productive ends. One participant said: 
...I think if you can learn how to harness it... if you can tap into the energy and direct it...if you can learn how to control and direct it and focus it on the right things, then the positives have huge potential.... huge...huge potential... I think people with what is called neurodiversity.... just look at some of the people who have neurodiversity in history.... There are people who have learnt how to use it and to harness it...I'd really like to learn how to....

In Assagioli's (1973) thesis, the psychological energy of will was purported as essential for fulfilling one's true potential in life. Assagioli asserted that will typified willers and wilful acts in an empirical and phenomenological sense and, suggesting therefore, that will was a measurable trait. The act of willing is indeed akin to Ryan and Deci's (2000) self-determination theory. The participants described will as the drive of $\mathrm{ADHD}$, as one participant said:

...I think ADHD got me through my corporate career but it nearly cost me my mental health completely.... having said that......without that drive I would never have been that successful...I don't think I'd have been as good a salesman as I became... and I don't think I would've been able to go back to my career once I'd had a breakdown and actually go on to become even more successful.... I don't think without ADHD I would have become as good a therapist....

The interpretation of will as a drive alludes to a type of behaviour called volition or purposive striving. Volition requires an individual to become energised by a strong desire to achieve something, then to strive relentlessly towards a threshold in which intrinsic motivation transmutes into a physical energy that drives performance and productivity (Deci and Vansteenkiste 2004). All the participants reported an abundance of physical energy as a positive aspect of their ADHD. It was viewed as a resource that bestowed several advantages, including feeling younger than their peers and being able to engage in different activities, such as sports, which certainly could have added to the participants positive sense of well-being (Gráinne et al. 2015).

\section{Humanity}

Humanity as the fourth core theme conceptualised the participants reports about their social behaviour. Defining subthemes are social intelligence, humour, self-acceptance and recognition offeelings. Humphrey (1976) argued that social intelligence was creative intellect comprising social awareness, attitude, an ability to initiate and manage relationships, as well as complex social change. All the participants described an ability to initiate social conversations with relative ease. They also reported having a positive mental attitude, which as a popular ideology, alleged that optimists naturally attract social success. In one study, optimists were found to enjoy a healthier life, because they tended to cope better with stress in comparison to pessimists (Conversano et al. 2010). In another study, optimists were found to exhibit trait extroversion and surgency, which are traits also associated with positive well-being (Blandon et al. 2010; Gale et al. 2013). These observations reflect in the report of one participant who said:

.... that is happiness as well...meeting other people... it's nice to connect to people. I find it nice to be able to connect to people or meet people and find out more about them... find out their stories that I don't know... it just makes me feel good you know....the positive social butterfly aspect I suppose....that's something I would say is ADHD related...you know... being a social butterfly....

Emotion contagion theory identifies a dynamic and engaging personality as a trait in individuals who succeed at transferring knowledge to others and are generally good at being persuasive in their social interactions (Hatfield et al. 1994). Persuasive people are contagious according to Gladwell (2000) because they exude positive energy. In large organisations, energy has been studied as a relational concept. In these studies, employees who were energizers tended to interact well with their colleagues, got promoted faster, sparked more innovation and generally performed well at work. Employees who were de-energizers tended to leave colleagues feeling low, bored and sapped of energy (Cross et al. 2003, 2012; Cross and Parker 2004). This observation echoed in the report of one participant who said:

...I didn't know that ADHDer's made great salesmen by the way.... you probably know that's another good career for an ADHD person and my son is a brilliant salesman... I went out with my friends for my first ever visit to a customer and came back with this huge order... and the customer actually rang back and said look...I've actually ordered far too much, can I cut the order back.....and I thought, oh, that's interesting...I can do this...

The participants described a penchant for humour as being eminent in the lives of people with ADHD. Even when asked what they would miss if their ADHD went away, all the participants said it would be their sense of humour. Research on humour found that it fostered well-being by encouraging tolerance and compassion towards self and others, a sense of identify with humanity and self-acceptance (Martin and Kuiper 1999; Martin 2001). The participants described self-acceptance as a positive attribute that demonstrated their willingness to tolerate self despite experiencing ADHD-related deficits and functional impairments. 
Self-acceptance is also important for accepting others (Linehan 1994). All the participants said that their ADHD made them more sensitive than other people, but that this enabled them to recognise feelings in self and be aware of the emotional states of others. This was reflected in the report of one participant who said:

...it's always to do with putting on other people shoes.... I don't know whether it's part of ADHD...I have related to other people with ADHD and they have this sort of over developed sense to identify with other people's emotions... it's what I've found...

It is possible that the participants in this study would rate high on emotional intelligence (EQ) (Mayer and Salovey 1997). But, research in EQ is relatively new, and it remains to be seen how it will report on complex emotional states and present an empirical body of knowledge on emotions. One participant alluded to the complexity of emotional states when he said:

...the emotional rollercoaster.... the highs and the lows....makes you feel alive....this is an intense experience emotionally whether it's part of ADHD....but I think it is....they say mood fluctuations are a negative aspect...but when you enjoy something or when you're excited about something you think.....all the enthusiasm.... and the energy....would I feel this if I didn't have ADHD.... would I have felt so much pleasure about the good news I just heard....

\section{Resilience}

Resilience, as the fifth core theme, characterised the participants reports about the strategies they used to cope with their ADHD. People who cope well with stress are said to be resilient, because they seem to possess protective strengths that enable them to flourish despite adverse conditions (Garmezy
1971; Segal and Yahraes 1978; McCraty et al. 2012). Defining sub-themes are self-regulation and sublimation. Selfregulation is a protective strength, but it can demand mental exertion or degrees of self-control that eventually could cause psychological fatigue (or ego-depletion), which in turn, would cause self-regulation (SR) to become ineffective or fail (Muraven and Baumeister 2000). Saying this, SR is also adaptive, which means that different SR strategies can be acquired, learnt and practised, which can offset the risk of psychological fatigue (Murray et al. 2015). Flexibility or adaptability, for instance, could be one such strategy. This was reported by one participant who said:

...You have to behave totally differently... and that's something... that... adaptability and being able to adapt yourself to any situation, I think would be something I'd attribute to ADHD...

The model of SR shown in Fig. 1 depicts the strategies that the participants acquired and used to cope with and/or manage their ADHD on a day-to-day basis. In this model, cognitive regulation (CR) and emotion regulation (ER) are depicted as the building blocks for behaviour regulation (BR), which in turn, acts like a feedback mechanism that either reinforces the strategy or signals that it needs to be adjusted or changed. In other words, the components that make up SR are CR, ER and BR. The bidirectional relationship between CR and ER, which is shown in the model, suggests that maintaining balance between the CR and ER is essential for effective BR (Murray et al. 2015). One participant reported on the importance of finding a balance between over-arousal (emotion) and boredom (cognition), when they said:

...it's a bit catch-22 because it is trying to find a balance between not being over aroused and not being bored.... life is always about finding a good balance and so it is that sort of walking a tight rope and try-
Fig. 1 Model of self-regulation (SR) strategies and processes (Murray et al. 2015; p. 7)

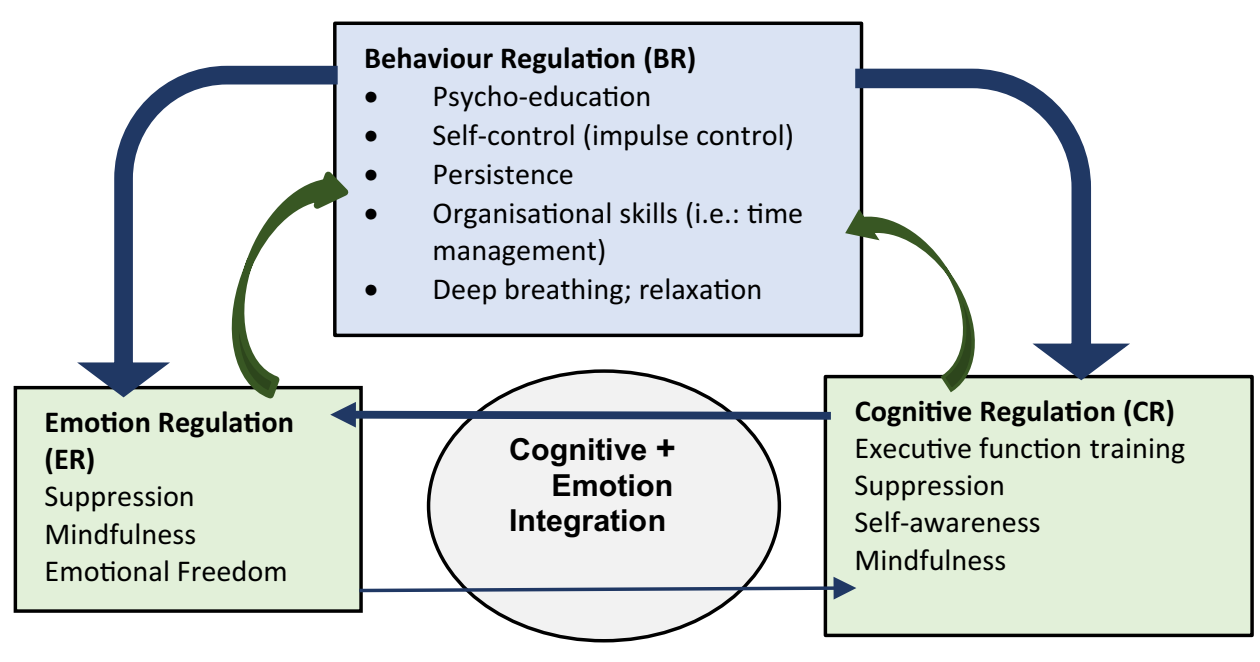


ing not to fall down on either side... one side is over arousal and one side is boredom...but trying to just keep on that little bit of rope and keep a steady pace and erm...just get it to a place where it feels ok...does that make sense?...

In the SR model in Fig. 1, the thicker arrow flowing from CR to ER suggests that top-down CR strategies have a stronger impact on ER. Strategies to enhance CR such as executive function (EF) training (e.g. complex span training) have been shown to be effective in this regard (Jaeggi et al. 2008; Harrison et al. 2013). One participant reported that they practised EF exercises and found them useful for enhancing concentration and attention. Other researchers such as Wranik et al. (2007) also found that ER could be enhanced by CR strategies like suppression, flexibility and reappraisal. Carver and Scheier (1981) studied the role of cognitive reappraisal in SR and found that it was effective for raising awareness about the strengths and limitations of self. In another study, cognitive reappraisal was reported as an adaptive strategy for regulating emotional responses to events (McRae et al. 2012). These views reflected in the report of one participant who said:

... I think taking and reducing some of the levels of trauma people have in their bodies and minds can make a lot of difference... so you know.... it's a whole package of stuff really.... at the heart of it for me...it's about self-monitoring and self-awareness...

It is possible that $\mathrm{CR}$ strategies exert more influence on ER, but Damásio (2010) contends otherwise. Damásio worked with patients who had severely impaired emotions but with their EFs intake. These patients could not plan simply tasks, make simply decisions or respond appropriately to questions. Damásio postulated that that it was due to these patients' inability to assess how they felt about their preferences. Clinical observations like this seem to suggest that emotion rather than cognition helps people gauge what is or is not important to them, before deciding on a course of action. One participant did say that they did not believe that SR strategies only came from cognitive-behavioural interventions, while other participants described strategies like suppression and mindfulness as being most useful. Indeed, these strategies have been found to be effective for containing distressing emotions like frustration, anger, controlling ruminations, or for directing one's attention to other mental contents (distraction) (Garland et al. 2011; Grabovac et al. 2011; Kane et al. 2007; Riediger et al. 2011). In almost of the stages of mindfulness practice, top-down (CR) and bottomup (ER) strategies coexist (Chiesa et al. 2013). De-centring, for instance, is a CR and ER strategies in mindfulness-based cognitive therapy that is used to teach patients how to view their thoughts and feelings as passing events, rather than as real reflections of self or others (Schman-Olivier et al. 2011). One participant described mindfulness as a useful intervention for SR by stating:

... he talked about ADHD and mindfulness very eloquently and of course it makes obvious sense... because an ADHD brain wants to go on and mindfulness actually wants to do quite the opposite...so whilst mindfulness practice is not the easiest thing for somebody with ADHD to do...even in a limited way...I find it quite helpful.... mindfulness practice, I think is potentially one of the most useful things that an ADHD person could learn...

Another participant described Emotional Freedom Technique as a useful intervention for ER. Emotional Freedom Technique (EFT) is said to be effective in dissipating negative emotions, reducing or eliminating pain, by finger tapping on the energy meridians targeted by traditional acupuncture, while vocalising positive affirmations (Feinstein 2012). A Delphi consensus poll of an expert panel of psychologists assessed a range of interventions, and they scored 3.8 for EFT, on a scale of 1-5, with a score of 3 being "possibly discredited" and 4 being "probably discredited" (Norcross et al. 2006). However, this participant said:

...I do something called E.F.T...Emotional Freedom Technique..... I use it on myself, everyday... that's an extremely useful technique for moderating arousal... grounding, calming and dealing with high levels of uncomfortable emotions...

All the participants described some type of BR strategy that they used like psycho-education persisting with SR goals like organisational skills, breathing exercises and relaxation techniques. It was clear, however, that while different strategies could be effective for SR, they all seem to require conscious or active attempts to self-regulate in the moment. These attempts are deliberate and allow for choice, whereas sublimation is an unconscious protective (or defence) mechanism that is not deliberate or by choice (Haan 1982). Sublimation is said to alter a person's perception of external or internal phenomena and in so doing protects against the effects of stress, anxiety, depression and so on (Freud 1936). Sublimation is akin to cognitive reappraisal in the sense of being an adaptive mechanism for self-preservation, as such, successful psychoanalytical treatment depends on sublimation. This process entails bringing repressed desires or wishes into conscious awareness so that they can be sublimated (or directed) towards more productive ends (Freud 1936). One participant alluded to this process when they said:

... there is strengths and weaknesses and how you can use your strengths, is by understanding I think, where 
your weaknesses are.... recognising those weaknesses, recognising those strengths and then maybe using those strengths to counteract those weaknesses.... I don't know.... that's it... as far as I'm concerned...

Freud (1910) used the terms substitute formations or return of the repressed to describe how repressed desires or wishes in the psyche eventually surface and manifest in various behaviours. Freud referred to Leonardo da Vinci as a classical case for sublimation, arguing that he sublimated his repressed homosexuality into scientific and artistic inventiveness. Freud said that sublimation "provided the energy for a great number of our cultural achievements" (1910, p. $50)$ and that "sexual curiosity could be sublimated in the direction of art" (1910, p. 156). These observations clearly associate sublimation with creativity, but the key point is that sublimation fosters psychological health. This came through in the report of one participant who said:

...we choose careers, we choose situations, we choose social environments that are friendlier to the way we are at processing information...

Nietzsche (1887/1967), like Freud, said that people were a collection of competitive drives (desires or wishes) with some drives at different times, taking more precedence than others (Gemes 2009). Nietzsche also explained that when some drives could not be expressed they turn inwards in a process called "the internalisation of man" and get repressed so far down the psyche that one no longer realises they have these drives (1887/1967). Nietzsche, like Freud, argued that repressed drives eventually find expression in disguised behaviours like religious fanaticism, in which individuals project anger and blame onto others. In other words, they become ill with resentment (Reginster 1997; Gemes 2009). The stigma and discrimination experienced by people with ADHD, or other mental health conditions, can cause resentment (Thornicroft et al. 2008). Resentment, however, can be sublimated in a positive way. Like one participant said:

... you appreciate the good things you have...you try deal with the traits that make your life difficult...I didn't choose to have ADHD.... but then you try to make the most of it so.... it's a way like rationalising and accepting these traits.... I think it's a healthy way of living and being... to try to focus on the positive aspects...

In Nietzsche's view, weaker drives (desires or wishes) could be channelled into a centred, unified whole or master drive and sublimated. Nietzsche made reference to the case of Richard Wagner, who revolutionised opera with his Gesamtkunstwerk (total work of art), as an example of how weaker drives channelled into a master drive could be sublimated in a way that a person "becomes all that they are capable of becoming" (1888/1967a, b). This notion came through in one report by a participant who said:

...It's all about channelling the energy.... channelling the energy and learning how to do that in a way that actually is useful, helpful and not overly intrusive and not overly stressed...

Nietzsche, like Freud, believed that sublimation was good for psychological health (1887/1967a, b). The Nietzschean concepts of amor fati (love of one's fate), eternal recurrence (the same thing always happens) and affirmation of life (say yes to life) asserted the importance of overcoming resentment and transcending nihilism (lack of purpose, or despair). In this way, people were free to enjoy life, felt motivated to pursue their goals and became happier and healthier (Reginster 1997; Gemes 2009).

\section{Transcendence}

Transcendence, as the last core theme, characterised the musical experience of one participant. Its defining sub-theme is appreciation of beauty and excellence. Appreciation of beauty and excellent (ABE) is a novel topic of research in positive psychology. It describes a process of noticing talent or beauty in the environment and associated feelings of awe, wonder, elevation and admiration (Haidt and Keltner 2004). In research about $\mathrm{ABE}$, it has been correlated with openness to experience, extraversion, agreeableness, absorption and positive affect (Shiota et al. 2006, Diessner et al. 2008, Littman-Ovadia and Lavy 2012). A distinct trait in musicians is said to be ABE. Güsewell and Ruch (2015) compared the personality profiles of 324 classical and non-classical musicians, amateur musicians and nonmusicians. They found that not only did all the musicians have better abilities to self-regulate due to their regular practicing sessions, but that they also experienced the specific emotional responsiveness that is associated with $\mathrm{ABE}$. The professional musicians also derived additional benefits from the emotional bonds they had with their colleagues. These findings resonated with the report of one participant who said:

... the whole thing about just starting a little jam session... was because we needed to do it and I just did it and that was brilliant.... beautiful experience....it was you know... it was really cool.... that's something I will never forget....and neither will my friend either...so that was something beautiful...

\section{Study limitations}

The phenomenological approach that we used had intuitive appeal, because it underscores the uniqueness and validity of personal knowledge and lived experience, as well as, the 
importance of understanding a person's construct of reality (Husserl 1983). However, this method also depends heavily on the participants use of language and ability to describe their views, perceptions and experiences in an articulate, expressive and reflective manner (Creswell and Poth 2017). Identifying and selecting participants capable of doing this can be challenging, but we managed to recruit suitable participants by using purposive sampling. Our sample size was relatively small, and the inclusion of females with ADHD may have offered different perspectives. However, small sample sizes are not unusual in phenomenological research. Giorgi (2008), for instance, suggested that "at least three participants offer a sufficient number of variations to come with a typical essence...... differences between individual experience and more general experiences of the phenomenon" (p. 37). While it does mean that generalising the findings of this study is not easy to do, we also argue that the positive aspects we found are relevant to other adults with ADHD regardless of sample size, age, gender or ethnicity. In qualitative research, generalising findings is not the aim; instead, the aim is to explore in depth and understand personal knowledge and lived experience (Creswell and Poth 2017). Besides other publications, including one international study reported on similar positive aspects associated with ADHD (Hallowell and Ratey 1995; White and Shah 2006, 2011; Mahdi et al. 2017). This does strengthen the reliability and transferability of our findings.

\section{Conclusion}

Six core themes (cognitive dynamism, courage, energy, humanity, resilience and transcendence), further defined by 19 sub-themes, constituted the main findings of this study. Most of these themes were catalogued in the CSV, which suggested they were relevant to people in general, with or without ADHD. The core themes-cognitive dynamism and energy - and sub-themes-divergent thinking, hyper-focus, nonconformist, adventurousness, self-acceptance and sublimation-were not catalogued in the CSV. We proposed these attributes as specific positive aspects of ADHD. The eminence of "energy" in ADHD life was certainly striking. Some participants described how they used, regulated or sublimated their energy into productive ends, while others expressed a desire to learn how to do this. Perhaps, it is time to reconsider vital energy. In positive psychology, vital energy is associated with behavioural traits like zest and vigour, which contain positively toned states that support mental health and well-being (Peterson and Seligman 2004).

This study also addressed the question in the disability research about "how we might reconsider the behaviours associated with ADHD so that they are seen as valuable and worthy of conservation?" (Freedman and Honkasilta 2017; p. 582). This question came from Garland-Thompson's (2012), compelling case to conserve disability, which she described as "preserving intact, keeping alive and encourage to flourish" disability in society. GarlandThompson argued for sociocultural ideas and norms about disability to be reshaped. She recommends a move away from eugenic logic, which proposes the elimination of disability in society because it causes too much "pain, disease, suffering, functional limitations, abnormality, dependence, social stigma and economic disadvantage", towards an understanding of disability as a benefit and resource for society to keep or conserve. From this viewpoint, we argue that the positive aspects of ADHD found in this study are benefits, resources, skills or strategies that can be used to mediate and/or compensate for ADHD-related deficits or impairments.

This is a study that reaches out to people with lived experience of ADHD: service users, patients, family members, carers, partners, to say that not all symptoms of ADHD are maleficent. Recovery, high functionality and flourishing with ADHD are possible. Too often people with lived experience hear about ADHD in relation to deficits, functional impairments and associations with substance misuse, criminality or other disadvantages on almost every level of life (school, work, relationships). Perhaps other researchers should replicate this study or undertake other research to document attributes that can promote or sustain well-being and flourishing in ADHD life. This emerging field of ADHD research is much needed. Findings from such research may appeal to practitioners who utilise cognitive-behavioural therapy, coaching or other psychological or behavioural interventions to treat or support people with ADHD. This study affirms the positive human qualities, assets and attributes in ADHD that can promote and sustain high functioning and flourishing.

Acknowledgements We thank the people who gave up their time to participate in this study. We also thank the Executive Committe Members of the UK Adult ADHD Network (https://www.UKAAN.org) for their advice and support.

\section{Compliance with ethical standards}

Conflict of interest The author(s) disclosed receipt of the following potential conflicts of interest. J. Sedgwick has received speaker's honoraria from Shire and receives an educational grant towards $\mathrm{PhD}$ tuition fees and conference costs from the Royal College of Nursing (RCN) Foundation. P. Asherson has received funds for consultancy on behalf of KCL to Shire, Eli-Lilly, and Novartis, regarding the diagnosis and treatment of ADHD, and has received educational/research awards from Shire, Eli-Lilly, Novartis, Vifor Pharma, GW Pharma and QbTech and is a speaker at sponsored events for Shire, Eli-Lilly, and Novartis. All funds are used for studies of ADHD. The other author declared no potential conflicts of interest with respect to the research, authorship and/or publication of this article. 
Ethical standard All procedures performed in studies involving human participants were in accordance with ethical standards of the institutional and/or national research committee and with the 1964 Helsinki Declaration and its later amendments or comparable ethical standards.

Informed consent Informed consent was obtained from all individual participants included in this study.

Open Access This article is distributed under the terms of the Creative Commons Attribution 4.0 International License (http://creativeco mmons.org/licenses/by/4.0/), which permits unrestricted use, distribution, and reproduction in any medium, provided you give appropriate credit to the original author(s) and the source, provide a link to the Creative Commons license, and indicate if changes were made.

\section{References}

Able SL, Johnston JA, Adler LA, Swindle RW (2007) Functional and psychosocial impairment in adults with undiagnosed ADHD. Psychol Med 37(1):97-107

Assagioli R (1973) The act of will. Penguin Books, New York

Babbie ER (1973) Survey research methods. Wadsworth, Belmont

Becker HS (1963) Outsiders: studies in the sociology of deviance. The Free Press, New York

Bernfort L, Nordfeldt S, Persson J (2008) ADHD from a socio-economic perspective. Acta Paediatr 97(2):239-245

Blandon AY, Calkins SD, Keane SP, O'Brien M (2010) Contributions of child's physiology and maternal behavior to children's trajectories of temperamental reactivity. Dev Psychol 46:1089-1102

Burnard P, Gill P, Stewart K, Treasure E, Chadwick B (2008) Analysing and presenting qualitative data. Br Dent J 204:429-432

Carter S (1996) Integrity. Basic Books, New York

Carver CS, Scheier MP (1981) Attention and self-regulation: a controltheory approach to human behavior. Springer, New York

Chiesa A, Serretti A, Jakobsen JC (2013) Mindfulness: top-down or bottom-up emotion regulation strategy? Clin Psychol Rev 33:82-96

Conversano C, Rotondo A, Lensi E, Vista OD, Arpone F, Reda MA (2010) Optimism and its impact on mental and physical wellbeing. Clin Pract Epidemiol Ment Health 6:25-29

Cooper JM (1998) The unity of virtue. Soc Philos Policy 15(01):233-274

Creswell JW, Poth CN (2017) Qualitative inquiry and research design: choosing among five approaches. Sage, Thousand Oaks

Cross R, Parker A (2004) The hidden power of social networks: understanding how work really gets done in organizations. Harvard Business School Press, Boston

Cross R, Baker W, Parker A (2003) What creates energy in organizations? Sloane Manag Rev 44(4):52

Cross R, Gray P, Gerbasi A, Assimakopoulos D (2012) Building engagement from the ground up: how top organizations leverage networks to drive employee engagement. Org Dyn 41:202-211

Csikszentmihályi M, Csikszentmihályi IS (1988) Optimal experience: psychological studies of flow in consciousness. Cambridge University Press, Cambridge, pp 5-35

Damásio AR (2010) Self comes to mind: constructing the conscious brian. Pantheon Books, New York

Deci EL, Vansteenkiste M (2004) Self-determination theory and basic need satisfaction: understanding human development in positive psychology. Ricerche di Psicologia 27:23-40

Diessner R, Solom RC, Frost NK, Parsons L, Davidson J (2008) Engagement with beauty: appreciating natural, artistic, and moral beauty. J Psychol 142(3):303-329
Epstein JN, Loren REA (2013) Changes in the definition of ADHD in DSM-5: subtle but important. Neuropsychiatry (London) 3(5):455-458

Feinstein D (2012) Acupoint stimulation in treating psychological disorders: evidence of efficacy. Rev Gen Psychol 16:364-380

Fitzgerald M (2010) Attention-deficit hyperactivity disorder link to genius, Thursday, 4 February 2010. http://news.bbc.co.uk/1/hi/ health/8496955.stm. Accessed 1 May 2018

Freedman JE, Honkasilta SM (2017) Dictating the boundaries of ab/ normality: a critical discourse analysis of the diagnostic criteria for attention deficit hyperactivity disorder and hyperkinetic disorder. Disabil Soc 32(4):565-588

Freud S (1910) Leonardo Da Vinci and a memory of his childhood (trans: Tyson A, Strachey EdJ). W.W. Norton \& Company, New York

Freud A (1936) The ego and mechanisms of defence, in "The Writings of Anna Freud", vol 2. International University Press, New York

Gale CR, Booth T, Mõttus R, Kuh D, Deary IJ (2013) Neuroticism and extraversion in youth predict mental wellbeing and life satisfaction 40 years later. J Res Pers 47(6):687-697

Garland EL, Boettiger CA, Howard MO (2011) Targeting cognitiveaffective risk mechanisms in stress-precipitated alcohol dependence: An integrated biopsychosocial model of automaticity, allostasis and addiction. Med Hypotheses 76(5):745-754

Garland-Thomson R (2012) The case for conserving disability. J Bioeth Inq 9(3):339-355

Garmezy N (1971) Vulnerability research and the issue of primary prevention. Am J Orthopsychiatry 41:101-116

Gemes K (2009) Freud and Nietzsche on sublimation. J Nietzsche Stud $38: 38-59$

Giorgi A (2008) Difficulties encountered in the application of the phenomenological method in the social sciences. Indo-Pac J Phenomenol 8(1):1-9

Gladwell M (2000) The tipping point. Little Brown, London

Glaser BG, Strauss AL (1967) The discovery of grounded theory: strategies for qualitative research. Aldine Publishing Co, Chicago

Grabovac AD, Lau MA, Willet BR (2011) Mechanisms of mindfulness: a Buddhist psychological model. Mindfulness 2(3):154-166

Gráinne L, Watkinson C, Brage S, Morris J, Tuxworth B, Fentem P, Griffin S, Simmons R, Wareham N (2015) Mortality benefits of population-wide adherence to national physical activity guidelines: a prospective cohort study. Eur J Epidemiol 30:71-79

Guilford JP (1967) The nature of human intelligence. McGraw-Hill, New York

Güsewell A, Ruch W (2015) Character strengths profiles of musicians and non-musicians. J Arts Hum 4(6):1-17

Haan N (1982) The assessment of coping, defence, and stress. In: Goldberger L, Breznitz S (eds) Handbook of stress: theoretical and clinical aspects. Collier Macmillan Publisher, London, pp 254-269

Haidt J, Keltner D (2004) Appreciation of beauty and excellence [awe, wonder, elevation]. In: Peterson C, Seligman MEP (eds) Character strengths and virtues: a handbook and classification. American Psychological Association and Oxford University Press, Washington, DC, pp 537-551

Hallowell EM, Ratey JJ (1995) Driven to distraction: recognising and coping with attention deficit disorder from childhood through adulthood. Touchstone, New York

Harrison TL, Shipstead Z, Hicks KL, Hambrick DZ, Redick TS, Engle RW (2013) Working memory training may increase working memory capacity but not fluid intelligence. Psychol Sci 24(12):2409-2419

Hatfield E, Cacioppo J, Rapson RL (1994) Emotional contagion. Cambridge University Press, New York

Hegel GWG (1807/1977) Phenomenology of the spirit (trans: Miller AV). Clarendon Press, Oxford 
Honneth A (1995) The struggle of recognition: the moral grammar of social conflicts (trans: Anderson J). MIT Press, Cambridge

Humphrey N (1976) The social function of intellect. In: Bateson PPG, Hinde RA (eds) Growing points in ethology. Cambridge University Press, Cambridge, pp 303-317

Husserl E (1983) Ideas pertaining to a pure phenomenology and to a phenomenological philosophy (trans: Kersten F). Martinus Nijhoff, The Hague (Original work published 1913)

Jaeggi SM, Buschkuehl M, Jonides J, Perrig WJ (2008) Improving fluid intelligence with training on working memory. Proc Natl Acad Sci 105(19):6829-6833

Jung CG (1921) Psychological types. In: Collected works of C.G. Jung, Vol. 6, Eds., G. Alder and RFC. Hull (1971), Princeton, NJ: Princeton University Press

Jung CG (1938a) Psychology and religion-the Terry lectures. In: Collected works of C.G. Jung, Vol. 11 (trans: Hull RFC) Eds. H. Read, M. Fordham and G. Adler (1958). Princeton University Press, Princeton

Jung CG (1938b) The archetypes of the collective unconscious, 2nd edn (trans: Hull, RFC) Bollingen series XX. Princeton University Press, Princeton (1959/1969)

Kane MJ, Brown LH, McVay JC, Silvia PJ, Myin-Germeys I, Kwapil TR (2007) For whom the mind wanders and when: an experiencesampling study of working memory and executive function in daily life. Psychol Sci 18(17):614-621

Kooij SJJ, Bejerot S, Blackwell A, Caci H, Casas-Brugué M, Carpentier PJ, Edvinsson D, Fayyad J, Foeken K, Fitzgerald M, Gaillac V, Ginsberg Y, Henry C, Krause J, Lensing MB, Manor I, Niederhofer H, Nunes-Filipe C, Ohlmeier MD, Oswald P, Pallanti S, Pehlivanidid A, Ramos-Quiroga JA, Rastam M, Ryffel-Rawak D, Stes S, Asherson P (2010) European consensus statement on diagnosis and treatment of adult ADHD: The European Network Adult ADHD, BMC Psychiatry 2010, 10:67. http://www.biome dcentral.com/1471-244X/10/67

Lesch KP (2018) Shine bright like a diamond: is research on high functioning ADHD at last entering the mainstream? J Child Psychol Psychiatry 59(3):191-192

Lincoln Y, Guba EG (1985) Naturalistic inquiry. Sage, Newbury Park

Linehan MM (1994) Acceptance and change: the central dialectic in psychotherapy. In: Hayes SC, Jacobson NS, Follette VM, Dougher MJ (eds) Acceptance and change: content and context in psychotherapy. Context Publishing, Reno, pp 73-86

Littman-Ovadia H, Lavy S (2012) Character strengths in Israel: Hebrew adaptation of the VIA Inventory of Strengths. Eur J Psychol Assess 28(1):41-50

Lubke GH, Hudziak JJ, Derks EM, van Bijsterveldt TC, Boomsma DI (2009) Maternal ratings of attention problems in ADHD: evidence for the existence of a continuum. J Am Acad Child Adolesc Psychiatry 48(11):1085-1093

Mahdi S, Vijoen M, Massuti R, Selb M, Almodayfer O, Karande S, de Vries PJ, Rohde L, Bölte S (2017) An international qualitative study of ability and disability in ADHD using the WHO-ICF framework. Eur Child Adolesc Psychiatry 26(10):1219-1231

Martin RA (2001) Humor, laughter, and physical health: methodological issues and research findings. Psychol Bull 127:504-519

Martin RA, Kuiper NA (1999) Daily occurrence of laughter: relationships with age, gender, and Type A personality. Int J Humor Res $12: 355-384$

Maslow AH (1951) Resistance to acculturation. J Soc Sci 7(4):26-29

Mayer JD, Salovey P (1997) What is emotional intelligence? In: Salovey P, Sluyter D (eds) Emotional development and emotional intelligence: implications for educators. Basic Books, New York, pp 3-31

McCraty R, Moor S, Lash M (2012) The resilience advantage (TM) workbook. Institute of HeartMath, Boulder Creek
McRae K, Gross JJ, Weber J, Robertson ER, Sokol-Hessner P, Ray RD, Gabrieli JDE, Ochsner KN (2012) The development of emotional regulation: an fMRI study of cognitive reappraisal in children, adolescents and young adults. Soc Cognit Affect Neurosci 7(1):11-22

Miranda MC, Barbosa T, Muszkat M, Rodrigues CC, Sinnes EG, Rizzuti S, Palma SM, Bueno OF (2012) Performance patterns in Conners' CPT among children with attention deficit hyperactivity disorder and dyslexia. Arq Neuropsiquiatr 70(2):91-96

Muraven M, Baumeister RF (2000) Self-regulation and depletion of limited resources: Does self-control resemble a muscle? Psychol Bull 26(2):247-259

Murray DW, Rosanbalm K, Christopoulos C, Hamoudi A (2015) Selfregulation and toxic stress: foundations for understanding self -regulation from an applied developmental perspective, OPRE Report 2015-21. U.S. Department of Health and Human Services, Washington, DC

Nietzsche F (1887/1967) Zur Genealogie der Moral (On the Genealogy of Morals) (trans: Kaufmann W, Hollingdale RJ). In: "On the Genealogy of Morals and Ecce Homo". Random House, New York

Nietzsche F (1888/1967a) Der Fall Wagner (The Case of Wagner) (trans: Kaufmann W). In: The birth of tragedy and the case of Wagner. Random House, New York

Nietzsche F (1888/1967b) Ecce homo: how one becomes what one is (trans: Kaufmann W). IN on the genealogy of morals and Ecce homo. Random House, New York

Norcross JC, Koocher GP, Garofalo A (2006) Discredited psychological treatments and tests: a Delphi poll. Prof Psychol Res Pract 37(5):515-522

Palinkas LA, Horwitz SM, Green CA, Wisdom JP, Duan N, Hoagwood K (2015) Purposeful sampling for qualitative data collection and analysis in mixed method implementation research. Adm Policy Ment Health 42(5):533-544

Patton MQ (1990) Qualitative evaluation and research methods. Sage, Newbury Park

Peterson C, Seligman MEP (2004) Character strengths and virtues: a handbook and classification. American Psychological Association and Oxford University Press, Washington, DC

Piirto J (1998) Understanding those who create, 2nd edn. Gifted Psychology Press, Scottsdale

Puthoff HE (2002) Searching for the universal matrix in metaphysics. Res News Oppor Sci Theol 2(8):22

Putman D (2001) The emotions of courage. J Soc Philos 32(4):463-470

Reginster B (1997) Nietzsche on ressentiment and valuation. Research 57:281-305

Repper J, Perkins R (2006) Social inclusion and recovery: a model for mental health practice. Bailliere Tindall, UK

Riediger M, Wrzus C, Wagner GG, Schmiedek F, Lindenberger U (2011) Is seeking bad mood cognitively demanding? Contrahedonic orientation and working memory capacity in everyday life. Emotion 11(3):656-665

Ryan RM, Deci EL (2000) Self-determination theory and the facilitation of intrinsic motivation, social development, and well-being. Am Psychol 55:68-78

Schman-Olivier Z, Albanese Z, Carlini S, Shaffer H (2011) Effects of trait mindfulness during buprenorphine treatment for heroin dependence: a pilot study. In: The American Journal on Addictions, 20, p 386, AAAP 21st Annual Meeting Poster Abstracts

Segal J, Yahraes H (1978) A child's journey. McGraw-Hill, New York

Seligman MEP (2012) Flourish: a visionary new understanding of happiness and well-being. The Free Press, New York

Seligman MEP, Csikszentmihalyi M (2000) Positive psychology: an introduction. Am Psychol 55(1):5-14. https://doi. org/10.1037/0003-066X.55.1.5 
Shiota MN, Keltner D, John OP (2006) Positive emotion dispositions differentially associated with Big Five personality and attachment style. J Posit Psychol 1(2):61-71

Thornicroft G, Brohan E, Kassam A, Lewis-Holmes E (2008) Reducing stigma and discrimination: candidate interventions. Int J Ment Health Syst 2(3): 1-7

Von Culin KR, Tsukayam E, Duckworth AL (2014) Unpacking grit: motivational correlates of perseverance and passion for long-term goals. J Posit Psychol 9(4):306-312

Walsh R, Vaughan F (1993) On transpersonal definitions. J Transpers Psychol 25(2):199-207

Weiss M (2016) The challenges of high functioning ADHD, University of Arkansas for Medical Sciences (UAMS), Psychiatric
Research Institute. file:///C:/Users/k1517101/Downloads/Parallel\%202B\%20-\%20Margaret\%20Weiss\%20(2).pdf. Accessed 24 Sept 2018

White HA, Shah P (2006) Uninhibited imaginations: creativity in adults with attention-deficit/hyperactivity disorder. Pers Individ Differ 40:1121-1131

White HA, Shah P (2011) Creative style and achievement in adults with attention-deficit/hyperactivity disorder. Pers Individ Differ 50:673-677

Wranik T, Barrett LF, Salovey P (2007) Intelligent emotion regulation: Is knowledge power? In: Gross JJ (ed) Handbook of emotion regulation. The Guilford Press, New York, pp 393-407

Zuss M (2012) The practice of theoretical curiosity. Springer, Brooklyn 